\title{
Presentation of a Model for a Competency-Based Succession Planning Model with Respect to Adjusting Role of Organizational Culture in Telecommunication Infrastructure Company of Iran (TICIR)
}

\author{
Sorush Niknamian \\ PhD, Board Member of Weston A Price Foundation, Washington DC, USA \\ Email: so.niknamian@gmail.com
}

\begin{abstract}
:
The current research aims to propose a competency-based succession planning model with respect to adjusting role of organizational culture in Telecommunication Infrastructure Company of Iran (TICIR). This study was conducted as an applied research in terms of objective and it was assumed as a descriptive survey by taking approach toward interpretative structural modeling. The statistical population of this study included two groups of experts and directors (Directors general, chairmen of offices, responsible experts and experts of TICIR Company). Primarily, in order to determine sample size for statistical population, 20 of experts were elected using non-randomized and selective sampling method and 340 members of the second statistical population were chosen by means of classified sampling technique including directors general, deputies of directors general, chairmen of offices, responsible experts and other experts of TICIR Company. The findings about succession planning model indicated that the variable of succession planning reached to a level higher than satisfactory rate therefore all of the related elements were placed higher than satisfactory level. Finally variable of organizational culture, as adjusting variable, was also placed at the level higher than satisfactory rate in this study. Hence, all of these variables reached to the level higher than satisfactory rate.
\end{abstract}

Keywords:

succession planning; competency; organizational culture; adjusting (variable); infrastructural communication

\section{Introduction}

The Telecommunication Infrastructure Company of Iran (TICIR) is one of the governmental fields which are responsible in Ministry of Information Technology and Communication. Structure of organizational manpower possesses a long history and they will reach to the retirement of their career in an early time in the future. With respect to vital role of this organization, management of this organization has put dealing with subject of succession planning for the organizational personnel as high on the agenda. On the other hand, some new and young workforces have jointed to the organization where they are assumed as the best and most available capital and source to meet this vital requirement. Accordingly, it necessitates for design and execution of a process to realize key goal of providing appropriate directors to avoid from cessation in playing this role and realization of organizational objectives which can be drawn within process of succession planning. Advancement in various cultural, political, economic, and social fields and especially technology has made the existing competitive environment as ambiguous, unstable, and extremely variant. Planning may provide suitable conditions for exposure to these uncertain conditions for the organizations. Many organizations employ planning of directors to cope with potential for destruction and ruining in organization and to meet environmental requirements and occurring events. Finally, organizations try to improve their own positions smartly and address development and recognition of administrative talents in their planning and assume them their growth and achievement in systematic and serious 
planning to manage talents and succession planning (Basiri .Abdolmajid, Sabegh, 2014).

Succession planning is a program through which appropriate persons are elected for incumbency of high-ranking administrative and major posts among qualified and talented personnel. The human talents in organization are identified for incumbency of major positions and jobs in subsequent years and they are gradually prepared to assume these jobs and tasks (Zeinoabedin Bidmeshki et al., 2014).

Several studies have examined succession planning as a challenging process and considered this process for improvement of business and definition of rules, timetable, and finding of appropriate successor as well as managing of succession planning may be deemed as a luckiness way for organizations. Researchers found that succession planning was an important trend in process of organizational survival cycle that is affected by some factors including strategy, culture, and also other factors (Michel et al., 2015). Over thirty years ago, workforce has been merged in most of countries and this has caused the professionals to acquire greater portion of knowledge and experience at higher level. The consequence of such knowledge transition to CEOs has caused vanishing of knowledge quickly when professional directors decided to retire from services within short time (Kaplan, 2008).

Bassidy and Charan (2015) expressed that one of the foremost part of an executive job was to put knowledge acquired by a director over several years at disposal of the next leader. This is led the current director to achieve what is favorable for him/ her and at the same time to leave a kind of heritage of oneself accordingly the next director to move. Succession planning is deemed as the basis for tackling with shocking of manpower. As a director leave organization suddenly, it is a basic problem for an organization to lose the reputation. Succession planning is the continuance of the process for systematic recognition, assessment, and development of organizational leadership to improve organizational performance and it is required for evaluation of a candidate and election of a person who can fulfill this key role (Dessler, 2008).

Competency is defined according to this point that how a person is elected, what $\mathrm{s} / \mathrm{he}$ knows and what $\mathrm{s} /$ he does. And some other factors are important in this regard including knowledge, communication, technical skills, distinct thought, emotion, values and activities which are led to an efficient function (Cross, 2010). In fact, competency describes characteristics of personnel they need to them for doing of their tasks properly (Kotonen et al., 2012). Competency management comprises of a group of merits or a list of tasks for apprentice who needs to acquire or execute them so that to be considered as a superior or competent person in terms of occupational aspect. Creation of competency-based management includes several advantages at individual and organizational level. The value-added advantage for an organization is owed to enhance competitive position of the organization, possession of suitable personnel for different jobs, facilitation of employment process, and constant development of personnel according to their requirements. This, in turn, leads to better performance of personnel, improvement of commitment in personnel, and finally enhancement of performance in personnel (Sanghi, 2007).

In their analysis on management process of succession planning and adjusting role of organizational culture, Mugo et al. (2015) showed that organizational culture affected codification of organizational strategies and succession management plans by common values and beliefs existing between organizational members. Skorkova (2016) proposed model of competencies in public sector. Also theory of competency, concept of comprehensive competency management, and inclusive necessity for evaluation of managerial competency has been examined in this study. Dubois et al. (2015) conducted a survey to interpret relationship among competency of directors and achievement of governmental organizations. Their research sample included 150 veteran directors who were elected from public offices. The results of their study showed that there was direct and significant relationship among organizational achievement of governmental organizations so that meritocracy was identified as an essential principle in the aforesaid organizations. Edward (2015) explored risk of human resources and succession planning using an 
integrated model of personal and financial counseling in New York. Using an integrated model in this survey, succession planning was investigated by considering the role of personal and financial advisors in household businesses. Their findings indicated that this process was followed by growing business, improvement in profitability and reduction in interpersonal differences. Santora, Joseph C, and Bozer (2015) investigated role of succession planning in constancy and stability of non-profit organizations by considering of strategic participation by human resources. The results these investigations showed that leadership competencies and skills were assumed as the prerequisites needed for appropriate execution of succession planning which could guarantee for organizational stability and persistence. Pandy and Sharma (2014) conducted a survey under title of 'Succession Planning Practices and Challenges: Study of Indian Organizations' to study on succession planning in 16 organizations in the fields of ITES, IT, diversified jobs, automotive, and other industries. Their finding showed that $66 \%$ of them believed the problem of finding a successful management candidate was the foremost need for succession planning.

Abbasi et al. (201b) reviewed relationship among competency and succession planning at higher education centers in Ilam Province. During recent decade, succession planning has been turned into one of the remarkable subjects. The current research has dealt with factor of competent selection among effective factors in succession planning. The results of study indicated that there was positive and significant relationship among meritocracy and the related dimensions with succession planning at higher educational centers in Ilam province. Taboly et al. (2015) examined relationship among succession planning with organizational thriving. Their results showed that the effective human resources and a process needed for study on organizational thriving in order to realize such effectiveness by a program similar to succession planning. Zeinolabedin Bidmeshki et al. (2014) compared the status quo for succession planning and management of talent under favorable condition in higher education system. The finding showed that there was significant difference among current and favorable statuses for program of succession planning in public universities in Tehran in all of given dimensions and variable of commitment to systematic succession planning in both of existing conditions was recognized as the foremost variable.

In order to meet their future requirements for directors, many organizations, which are placed in path of destruction, lack a certain plan and they leave these activities to subject to the accident and passing of time and they operate as reactive when being exposed to the problems but those organizations, which look for preservation and enhancement of their positions, focus their planning on recognition and training of interorganizational administrative talents (initially) and extraorganizational ones. During previous decades, organization employed succession planning only for specific jobs but over the time the pioneering organizations tried to utilize more extensive concept under title of management of succession planning. In fact, given quick environmental changes, it is emphasized in formation and updating of treasure of talent dynamically and constantly instead of simply a plain program in succession planning (Bordbar et al., 2012).

According to the conducted studies, competency model is an important member in changing if individual and organizational structure which supports from training empowerment plan, performance management, the plan of jobs description, and succession planning (Ennis, 2008). It has been moved toward international occupational standards or competency models as a result of rising number of retired personnel and it aimed to cover the gap of skill and knowledge, nationalization of workforce, and attraction and maintenance of talented forces (Conner et al., 2014). The competency models are assumed as important in terms of succession planning because regardless of this process it is difficult to do several tasks including creating of relationship among main organizational competencies to occupational competencies, giving a transparent definition about talented personnel, accurate determination of competencies needed for present and future in organization, preparation of a basis for performance management by 
creation of a favorable workplace that is followed by favorable performance of personnel, creation of clear occupational expectations for the present and future, perfect job evaluation, and development of individual plan to contribute to the personnel to decrease the gap between the needed competencies for achievement (Rothwell, 2005).

There are some organizations which possess powerful directors where they could not survive without such personnel at all; however, these organizations may unwantedly lose these workforces because of several reasons including retirement, resignation, death and or even job promotion. Thus, it is required for prevention from creation of disruption in organizational processes to employ plans to provide competent forces. However, many organizations ignore this issue unfortunately and as they are aware of importance of this subject when it is in vain to do anything and organization is losing the valuable workforces. Therefore, it is necessary for existing of a systematic and purposive method and plan to upgrade scientific awareness to implement succession management and planning to determine key roles by talented and competent personnel. It has been proved those succession plans which are tied with occupational path for personnel, may improve spirit of personnel and their productivity. Those organizations, which support from occupational development by creating of chances for personnel to find new opportunities inside the organization and encouraging them to job motion, will more unlikely share them in developing of their job.

Whereas these personnel more unlikely look for several opportunities in organization if maintenance process is done duly in organization; overall, this is led to increase in job satisfaction among personnel. Nevertheless, there is problem in succession planning models in which despite effect of organizational culture on succession planning, succession planning models have ignored effect of this variable. Thus, designing of a model that can fill this gap may create more suitable structure for the organization and for this reason current research is intended to deal with this important subject. In today world competition, the companies which are active in ICT field especially TICIR Company can remarkably contribute to the country to achieve a position proportional to their valuable level. In this regard, human resources play a crucial role. Alternately, experiences and skills of personnel are considered as a source for which organization spend a lot of costs to acquire them. Nonetheless, organizational directors have forgotten role of these workforces because they think the experienced and skillful personnel always attend in the organization and they may not need to plans for human resource development while exiting of human resources imposes some costs to the organization since organization is required again to spend more time and cost for training of personnel. Hence, presentation of a competency-based succession planning model may provide this opportunity for organizations to train a competent person as future director before retirement of current manager and after retirement of previous manager a person is substituted with him/ her that organization ensures from competency and skill of such a person and thereby organization could continue their proper path. With respect to aforementioned subjects, the current research tends to present a competency-based succession planning model given adjusting role of organizational culture in TICIR Company. 
Research Conceptual Model

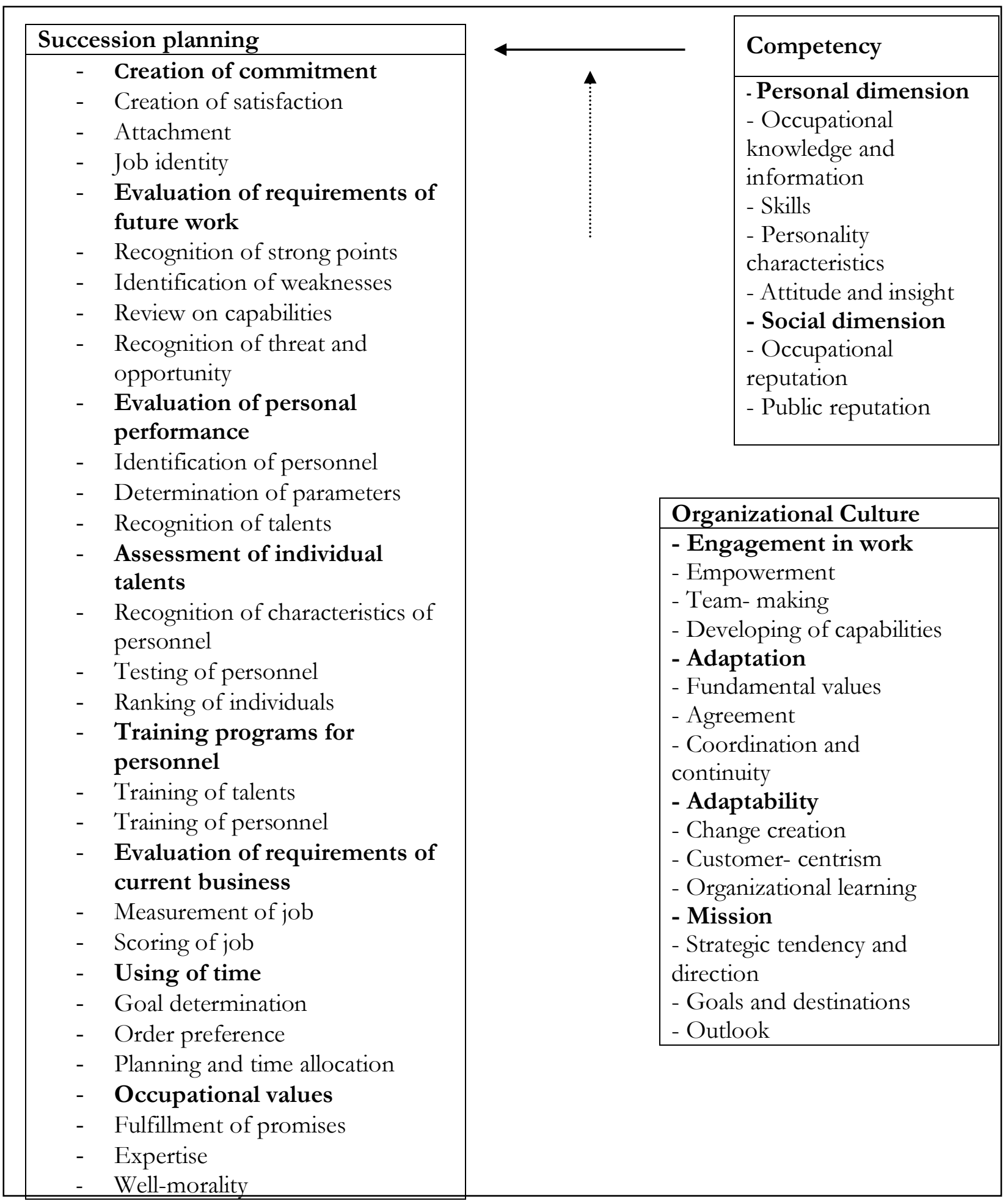

\section{Research Questions}

These questions are raised in this study as follows:

1. What are the indices for succession planning in TICIR Company?

2. Which are parameters of competency in TICIR Company? 
3. How is the condition of succession planning in TICIR Company?

4. How is the status of competency in TICIR Company?

5. How is the condition of organizational culture in TICIR Company?

6. What is the relationship among competency and succession planning in TICIR Company?

7. Is there any relationship among competency and succession planning with respect to adjusting role of organizational culture in TICIR Company?

8. What are the characteristics of succession planning in TICIR Company and how much the validity of succession planning model in TICIR Company?

\section{Research Methods}

This study is an applied research in terms of objective and it is descriptive survey in terms of method and it has been carried out by taking approach toward interpretative structural modeling. The statistical population of this study was composed of two groups: The first group was the experts who quantity was uncertain and dispersed and the second group comprised of all directors general, deputies of directors general, chairmen of offices, responsible experts and also other experts in TICIR Company throughout Iran where they were totally 2217 members. Using of non-randomized selective sampling method to determine sample size for first statistical population, we elected 20 respondents of experts by considering some criteria such as accessibility, scholar expertise in university and academic centers where they studied, having the relevant educational degrees concerning book or paper. To determine sample size for the second statistical population i.e. directors general, deputy of directors general, chairmen of offices, and responsible experts and other experts of TICIR Company, they were chosen by classified sampling method with 340 members.

\section{Data collection tools}

The questionnaire items are interpreted by Delphi technique out of focus group (experts) to determine and prioritization of dimensions and indices of competency-based succession planning in TICIR Company. The quantity of these questionnaires was 5 .

1. The first questionnaire was utilized to identify dimensions and indices of succession planning in TICIR Company. This questionnaire is completed by the experts.

2. The second questionnaire will be used for determination of dimensions and variables of competency in TICIR Company. This questionnaire is filled out by experts.

3. Third questionnaire will be utilized for measurement of succession planning status in TICIR Company. This questionnaire is completed by operational directors and corporate experts.

4. The fourth questionnaire will be employed for measurement of competency status in TICIR Company. This questionnaire is completed by operational directors and corporate experts.

5. The fifth questionnaire will be utilized for measurement of status of organizational culture in TICIR Company. This questionnaire is completed by operational directors and corporate experts.

Both content validity and construct validity were employed in this study to determine validity of questionnaires. After reading of books and essays regarding the research subject and study on questionnaires in other papers and researches, the needed items were designed for research variables to determine content validity and the codified questionnaires for research variables were examined by research masters. The exploratory factor analysis and confirmatory factor analysis were employed for review of construct validity of measurement tool (questionnaire) as well as appropriateness of psychometric criteria of questionnaires which were assumed as important defaults in structured equations. In order to determine internal reliability, rate of internal reliability was calculated for questionnaires of succession planning, competency, 
and organizational culture using Cronbach alpha coefficient and given that the Cronbach alpha coefficients were higher than (0.7) the internal reliability was confirmed for all three questionnaire. The questionnaires were distributed gathered by attendance and electronically at any phase.

\section{Discussion}

\subsection{Research Findings}

SPSS and IMOS software, Pearson's correlation test, Kolmogorov-Smirnov test, binominal test, frequency tables, Bazargan Standard table, factor analysis, modeling of structured equations with path analysis were utilized for statistical description and analysis and structural relations. Among total 340 participants in this study $69.1 \%$ of them were males and $30.9 \%$ were females in section of demographic data. The highest numbers for educational degrees in participants, BA degree (51.5\%) and high school diploma $(47.1 \%)$ were the most frequent rates among the participants. Similarly, 35 participants were chairmen of offices, 282 members were experts and responsible experts, and 23 participants included directors general and their deputies out of them $81.5 \%$ have been employed by official system and $18.5 \%$ of them were as contractual personnel.

Normality of studied variables was examined before analysis of research hypotheses. Kolmogorov-Smirnov test was employed for determination of assumption of normality of variables. The results of this test are given in the following table.

Table 1. Analysis on normality of research variables

\begin{tabular}{ccc}
\hline Variable & Kolmogorov-Smirnov & Value (-p) \\
\hline Succession planning & 0.068 & 0.077 \\
Competency & 0.074 & 0.083 \\
Organizational culture & 0.051 & 0.064 \\
\hline
\end{tabular}

Likewise, Pearson's correlation coefficient was utilized to determine relationship between variables. The resultant findings from correlation test are given in Table (2).

Table 2. Analysis on relationship between variables

\begin{tabular}{ccc}
\hline Variable & Kolmogorov-Smirnov & Value $(-\mathrm{p})$ \\
\hline Succession planning & 1 & $0.860^{* *}$ \\
Competency & $0.860^{* *}$ & 1 \\
\hline * Significant at level $0.05(\mathrm{p}<0.05) ;{ }^{* *}$ Significant at level 0.01 & $(\mathrm{p}<0.01)$
\end{tabular}

Given the Pearson's correlation coefficient and also this quantity ( $p$-value $=0$ ) there is significant and direct relationship among competency and succession planning in TICIR Company at level 0.01. The multivariate regression was utilized to review relationship between competency factors with succession planning in TICIR Company. The given results from regressive analysis and determination coefficient indicated variables of knowledge and information, skills, personality characteristics, attitude and insight, and public reputation affected significantly succession plan as predictors ( $\mathrm{p}$-value $<0.05$ ). Similarly, according to parameter of partial correlation coefficient among effective factors of competency on succession planning in TICIR Company, variable of public reputation has the maximum relationship with succession planning. 
Table 3. Table of regression coefficients for effective factors of competency on succession planning

\begin{tabular}{ccccc}
\hline Variable & $\begin{array}{c}\text { Standardized } \\
\text { coefficient }\end{array}$ & t-statistic & p-value & $\begin{array}{c}\text { Partial correlation } \\
\text { coefficient }\end{array}$ \\
\hline Knowledge and information & 0.245 & 6.488 & 0 & 0.335 \\
Skills & 0.322 & 8.074 & 0 & 0.405 \\
Personality characteristics & 0.191 & 5.620 & 0 & 0.294 \\
Attitude and insight & -0.109 & -2.813 & 0.005 & -0.152 \\
Professional reputation & 0.034 & 0.932 & 0.352 & 0.051 \\
Public reputation & 0.354 & 8.618 & 0 & 0.427 \\
\hline
\end{tabular}

With respect to adjusting role of organizational factor, goodness of fit indices in succession planning model, competency model, and the model among competency and succession planning is given in the following tables. There are several techniques for estimation of general goodness o fit with the observed data. The criteria of GFI, AGFI, RMSEA, NFI, NNFI, and CFI were used for assessment of goodness of fit in all models at this study.

Table 4. Fitness indices for succession planning model

\begin{tabular}{ccc}
\hline Index & Favorable statistic value & Reported value \\
\hline Root Mean Square Error of & $\leq 0.08$ & 0.036 \\
Approximation (RMSEA) & & \\
Chi2 ratio $\left(\chi^{2} / d f\right)$ & $\geq 3$ & 2.024 \\
Goodness of Fit Index (GFI) & $\geq 0.90$ & 0.921 \\
Adjusted Goodness of Fit & & 0.945 \\
Index (AGFI) & $>0.90$ & \\
Comparative Fit Index (CFI) & $>0.90$ & 0.910 \\
Normed Fit Index (NFI) & $>0.90$ & 0.987 \\
Tucker \& Lewis Index (TLI) & $>0.90$ & 0.941 \\
Incremental Fit Index (IFI) & & 0.956 \\
\hline
\end{tabular}

Table 5. Fitness indices for competency model

\begin{tabular}{ccc}
\hline Index & Favorable statistic value & Reported value \\
\hline Root Mean Square Error of & $\leq 0.08$ & 0.059 \\
Approximation (RMSEA) & & \\
Chi2 ratio $\left(x^{2} / d f\right)$ & $\geq 3$ & 2.280 \\
Goodness of Fit Index (GFI) & $\geq 0.90$ & 0.898 \\
Adjusted Goodness of Fit & $\geq 0.90$ & 0.923 \\
Index (AGFI) & $\geq 0.90$ & 0.901 \\
Comparative Fit Index (CFI) & $\geq 0.90$ & 0.924 \\
Normed Fit Index (NFI) & $\geq 0.90$ & 0.996 \\
Tucker \& Lewis Index (TLI) & $\geq 0.90$ & 0.909 \\
Incremental Fit Index (IFI) & & \\
\hline
\end{tabular}


Table 6. Fitness indices for model among competency and succession planning with respect to adjusting role of organizational culture

\begin{tabular}{ccc}
\hline Index & Favorable statistic value & Reported value \\
\hline Root Mean Square Error of & $\leq 0.08$ & 0.061 \\
Approximation (RMSEA) & & \\
Chi2 ratio $\left(x^{2} / d f\right)$ & $\geq 3$ & 1.924 \\
Goodness of Fit Index (GFI) & $\geq 0.90$ & 0.942 \\
Adjusted Goodness of Fit & $\geq 0.90$ & 0.980 \\
Index (AGFI) & $\geq 0.90$ & 0.911 \\
Comparative Fit Index (CFI) & $\geq 0.90$ & 0.965 \\
Normed Fit Index (NFI) & $\geq 0.90$ & 0.897 \\
Tucker \& Lewis Index (TLI) & $\geq 0.90$ & 0.899 \\
Incremental Fit Index (IFI) & & \\
\hline
\end{tabular}

With respect to the given indices, these models are suitable fitted.

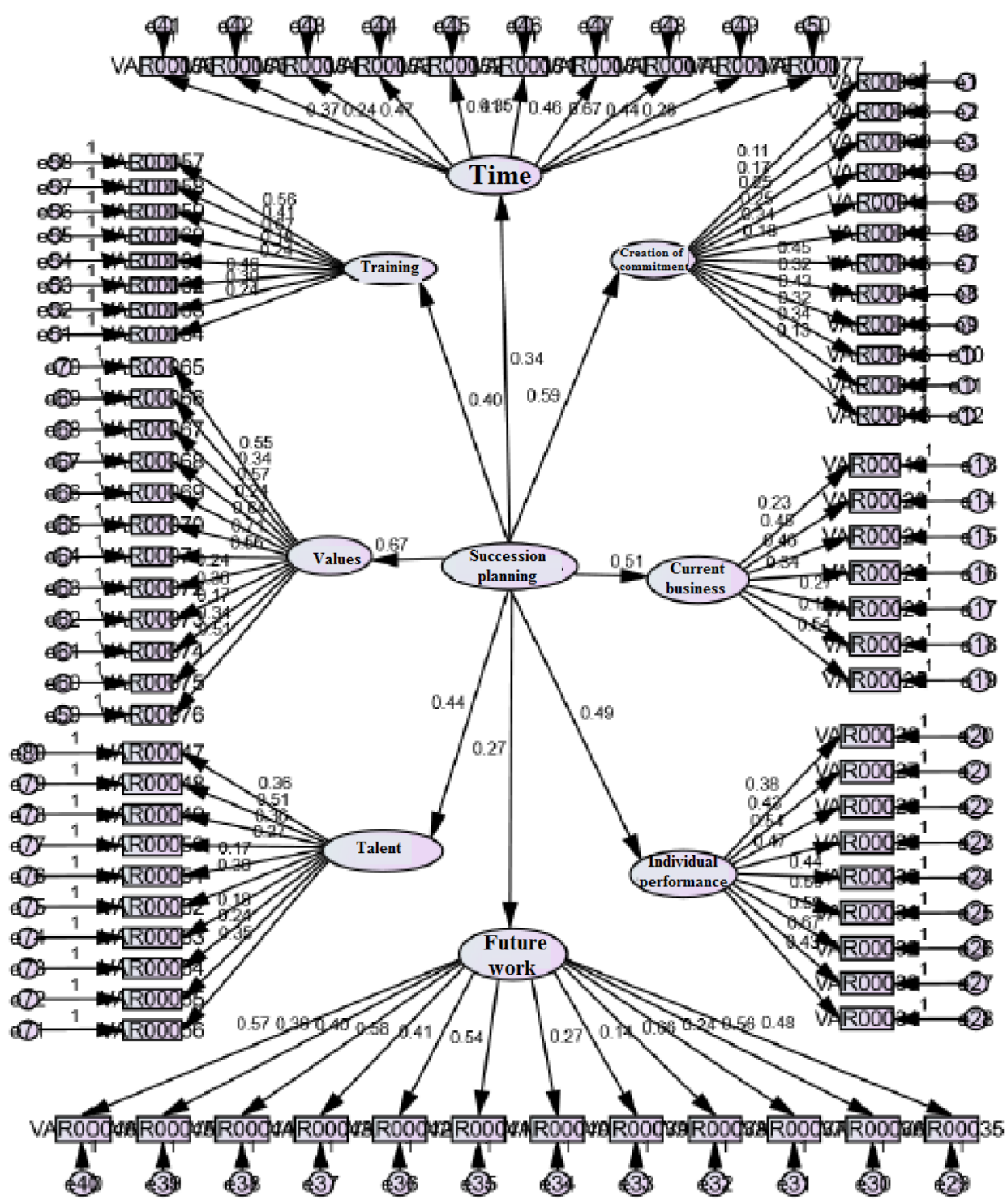

Figure 1. Diagram for path analysis of variable of succession planning 
Likewise, the results given in Table 7 indicate path coefficients, quantity of t-statistic, pvalue, and analysis on type of relation.

\begin{tabular}{|c|c|c|c|c|}
\hline Studied relationship & $\begin{array}{c}\text { Path } \\
\text { coefficient }\end{array}$ & t-value & p-value & $\begin{array}{l}\text { Type of } \\
\text { relationship }\end{array}$ \\
\hline $\begin{array}{l}\text { Succession planning } \rightarrow \\
\text { (competency } * \text { culture) }\end{array}$ & 0.365 & $11.076^{* *}$ & 000 & Incremental \\
\hline $\begin{array}{l}\text { Succession planning } \rightarrow \\
\text { (individual dimension } * \text { culture) }\end{array}$ & 0.475 & $6.439^{* *}$ & 000 & Incremental \\
\hline $\begin{array}{l}\text { Succession planning } \rightarrow \\
\quad \text { (knowledge } * \text { culture) }\end{array}$ & 0.271 & $8.745^{* *}$ & 000 & Incremental \\
\hline $\begin{array}{l}\text { Succession planning } \rightarrow \\
\quad(\text { skill } * \text { culture })\end{array}$ & 0.424 & $9.172^{* *}$ & 000 & Incremental \\
\hline $\begin{array}{l}\text { Succession planning } \rightarrow \\
\quad \text { (personality } * \text { culture })\end{array}$ & 0.172 & $6.7341^{* *}$ & 000 & Incremental \\
\hline $\begin{array}{c}\text { Succession planning } \\
* \text { culture })\end{array}$ & 0.663 & $14.324^{* *}$ & 000 & Incremental \\
\hline $\begin{array}{l}\text { Succession planning } \rightarrow \\
\text { (social dimension } * \text { culture })\end{array}$ & 0.645 & $7.591^{* *}$ & 000 & Incremental \\
\hline $\begin{array}{c}\text { Succession planning } \rightarrow \\
\text { (professional reputation } * \\
\text { culture) }\end{array}$ & 0.491 & $7.523^{* *}$ & 000 & Incremental \\
\hline $\begin{array}{c}\text { Succession planning } \rightarrow \\
\text { (public reputation } * \text { culture) } \\
\text { Succession planning }\end{array}$ & 0.465 & $8.217^{* *}$ & 000 & Incremental \\
\hline
\end{tabular}

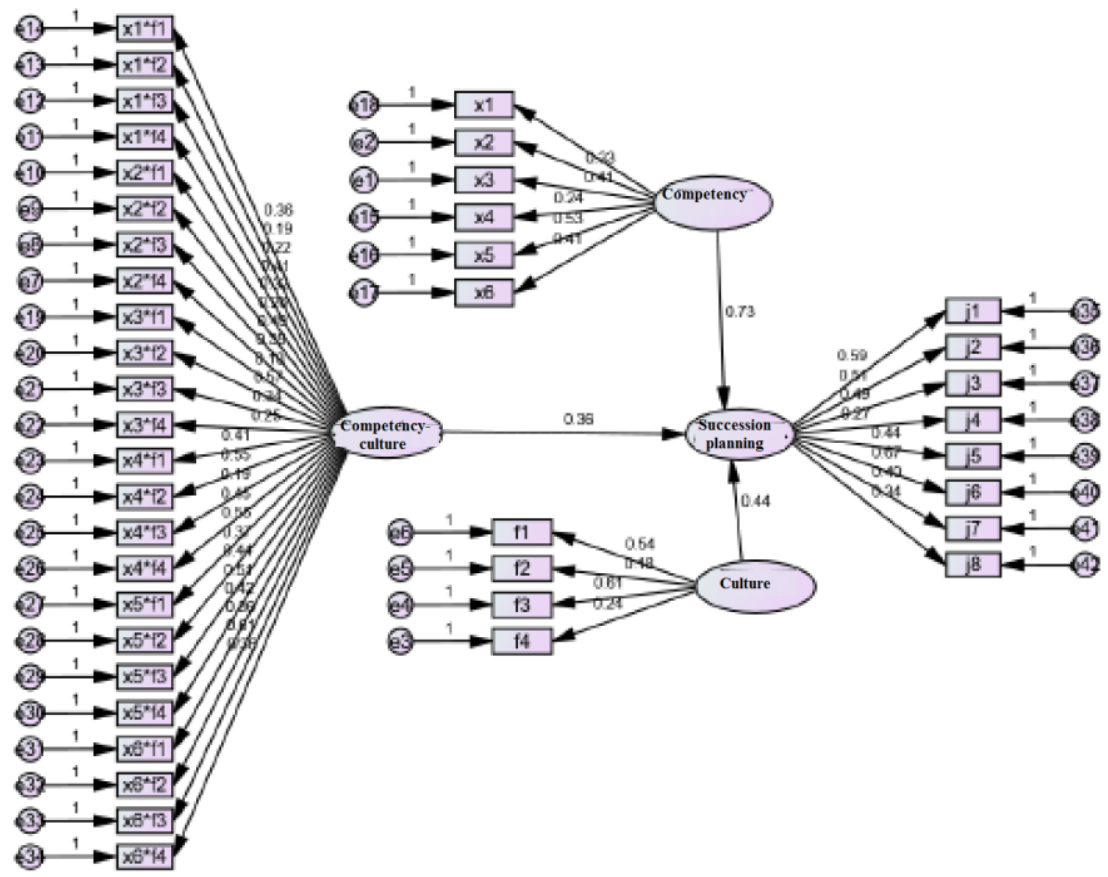

Figure 2. Diagram of path analysis among succession planning and competency with respect to adjusting role of organizational culture 
With respect to gram of path analysis in Fig $(2)$ and the given t-value $(1096<11.076)$ in Table $(7)$ and also calculated p-value $(0<0.05)$, null hypothesis is rejected and it can be concluded that there is relationship among competency and succession planning with respect to adjusting role of organizational culture in TICIR Company.

\subsection{Discussion}

1. What are the indices for succession planning in TICIR Company?

The factor analysis method was used for variable to give answer to this question by analysis them into main variable and Varimax rotation. Based on the results derived from factor analysis, 80 sub-items (questions) have been summarized about succession planning factors into 8 factors. These factors include commitment, evaluation of current business requirements, assessment of individual performance, evaluation of future work, assessment of individual talents, training programs for personnel, occupational values and use of time. KMO test value was 0.801 for quality of sampling that was reasonable quantity. The results of this question are consistent with findings in studies done by Zeiolabedin Bidmeshki et al. (2014), Shojaei (2014), and Rothwell (2005).

2. Which are parameters of competency in TICIR Company?

The factor analysis method was also employed for variable to respond to this question by analysis them into main variable and Varimax rotation. According to the results came from factor analysis, 24 sub-items (questions) relating to competency factors were summarized into 2 factors. These factors comprise of first factors (individual dimension) and second factor (social factor). KMO value was 0.781 for quality of sampling that was reasonable quantity. Concerning this question, Skorkova (2016) also conducted an investigation under title of Competency models in public sector. According to statement of Skorkova, competency is a factor which enables personnel to cope with changes. Private sector has found the response to this problem in competency-based management. Competency models are also assumed as key tools in systems of human resources.

3. How is the condition of succession planning in TICIR Company?

The findings showed it in the condition of succession planning that way of building of this variable is composed of 8 questions with 5 choices. The observed mean was 3.17 for this variable while the related median was seen 3.13, mode (2.89), standard deviation (0.645), minimum (1.38), and maximum (4.31). Similarly, it was characterized that the mean rate of variable of succession planning was 3.17 therefore it can be concluded according to Bazargan scale that variable of succession planning has been placed at the level higher than satisfactory rate. The results of this question are consistent with the findings in studies conducted by Whitman and Valpuesta (2010), Rothwell (2005), Conger and Fulmer (2003), Kim (2006), Bidmeshki et al. (2014), Kazemi Moghadam et al. (2012), Derakhshideh and Ansari (2014), and Mehrtak et al. (2014).

4. How is the status of competency in TICIR Company?

The observed mean was 3.48 for this variable, and the related median was seen 3.63, mode (4.12), standard deviation (0.623), minimum (1.21), and maximum (4.53). Similarly, the mean value of variable competency is 3.48 where according to Bazargan scale it can be concluded that the variable of competency has been placed at the higher level than satisfactory rate. The findings of this hypothesis are consistent with studies done by Yeganegi (2010), Fang et al. (2010), Ranaei et al. (2012), Pasbani et al. (2012), Skorkova (2016), Dubois et al. (2015), Elenna et al. (2015), Santora, Joseph C, and Bozer (2015).

5. How is the condition of organizational culture in TICIR Company?

Based on the results derived from factor analysis, 60 sub-items (questions) about factors of organizational factors were summarized into 4 factors. These factors include the first factor (adaptation), the second factor (mission), and third factor (engagement in 
business), and fourth factor (adaptability). According to the findings, KMO value is 0.841 for quality of sampling that is reasonable quantity. Likewise, with respect to significance of Bartlett's test ( $p$-value $<0.05)$, the necessary conditions were satisfied for execution of factor analysis. The observed mean is 3.26 for this variable and the related median is seen 3.30 , mode (3.05), standard deviation (0.555), minimum (1.47), and maximum (4.25). Likewise, the mean for variable of organizational culture is 3.26 therefore it can be concluded according to Bazargan scale that variable of organizational culture has been placed at the level higher than satisfactory rate. The results of this question are consistent with the findings from studies of Monavarian (2003), Pakdel et al. (2014), Monavarian and Bakhtaei (2007), and Ardalan et al. (2008).

6. What is the relationship among competency and succession planning in TICIR Company?

Given the value of Pearson's correlation coefficient and also the quantity ( $p$-value $=0$ ) there was significant and direct relationship among competency and succession planning in TICIR Company at level 0.01. Studies indicated that developing of managerial competencies was followed by efficient improvement and subsequently competency dimensions should be comprehensively developed among directors to achieve efficient management. The results of this question are consistent with the findings from studies of Monavarian (2003), Pakdel et al. (2014), Monavarian and Bakhtaei (2007), Ardalan et al. (2008), Pazhoohesh Zakeri (2015), Abbasi et al. (2009), Rothwell (2005), Conger and Fulmer (2003), Kim (2006), and Romjek (2008).

7. Is there any relationship among competency and succession planning with respect to adjusting role of organizational culture in TICIR Company?

With respect to diagram of path analysis of variable of succession planning and t-value $(1096<11.076)$ as well as calculated $\mathrm{p}$-value $(0<0.05)$, null hypothesis is rejected and it can be concluded that there is relationship among succession planning in respective of adjusting role of organizational culture in TICIR Company. The results of this question are consistent with the findings of studies done by Basiri and Sabagh (2015), Shabankareh et al. (2015), Jarbou (2010), Golipour et al. (2012), Bordbar et al. (2012), and Jokar and Maleki (2017) as well.

8. What are the characteristics of succession planning in TICIR Company and how much the validity of succession planning model in TICIR Company?

The criteria of GFI, AGFI, RMSEA, NFI, NNFI, and CFI were employed in this study to assess goodness of fit for all of models. With respect to the given indices, models of succession planning (Table 4), competency (Table 5), and the model among competency and succession planning (Table 6 ) are suitably fitted.

According to the findings it can be concluded that variable of succession planning is placed at the level higher than satisfactory rate. Therefore all elements of this variable are placed at the position higher than satisfactory level, except variable of commitment which is placed at good level. Accordingly, it is suggested about factor of organizational commitment to the directors to provide personnel's satisfaction by employing improvement and progress in li line with their occupational path because job satisfaction causes organizational commitment. Namely, job satisfaction is assumed as precondition for organizational commitment. Thus, they should pay due attention to way of promotion of personnel and prepare the ground to achieve individual and organizational goal by implementation of accurate management on processes of occupational promotion for personnel logically and precisely. 


\section{Conclusion}

Based on the results of this study, it can be concluded that variable of competency has been placed at the level higher than satisfactory condition. Therefore, all elements of this variable are in the position higher than satisfactory level. According to the given results about individual dimension, the mean value of this variable is (3.56) which is higher than satisfactory level. Thus, it is suggested to the organization to improve related education and expert trainings for personnel in order to increase their professional knowledge and information for doing of occupational activities. To this end, various training courses should be held with respect to expertise in personnel in organization. Based on the findings from this study, it can be concluded that variable of organizational culture has been also at the level higher than satisfactory position. Therefore, all elements of this variable are placed as high level than satisfactory rate. Variable of mission is placed at level higher than satisfactory position. Thus, it is suggested to leaders to clarify organizational objectives perfectly for this personnel so that organizational personnel to be aware of the tasks which should be done thereby the organization to achieve in the long run. Similarly, organization needs to codify clear strategies for the future so that strategic path of the organization not to be ambiguous to personnel.

Finally, given that the presented model in this study enjoys favorable validity and it is aligned with theoretical patterns and scientific bases; accordingly, whereas organizational culture totally forms behavior of organizational members including directors and personnel at different levels thus it can affect organization in creation of change and strategic orientation noticeably and alternately the basis and framework for determination of competent subject is relatively affected by organizational culture to great extent their elements should be improved. Therefore, certain efforts and planning should be taken for upgrading and improvement in each of dimensions and parameters of organizational culture because organizational culture directly and indirectly intervenes in determination of competency level in individual and it plays an important role in creation of consistency in the given behaviors of personnel. The studies have indicated that rather than this point election of personnel for incumbency of future positions is assumed as one of the foremost success factors in succession planning, organizational culture should be also developed and a type of positive attitude should be taken toward able personnel and it should not be only focused on their background. Thus, attention should be more paid to implementation of meritocracy culture in organization so that to prepare suitable platform to train competent personnel in the organization since organizational culture is composed of a system of common values which guide behavior in personnel and acts as an important factor in achievement for execution of succession planning. Moreover, specific legal criteria and methods should be employed in systems of attraction of workforces, appointment and promotion thereby to pave the way needed for establishment of a meritocratic system and developing of meritocracy in organization.

\section{References}

Ardalan, Mohammad Reza et al. (2008). Analysis of relationship among unity of Individualorganization and organizational culture in public universities at west of Iran (Hamedan, Kermanshah, and Kurdistan), Quarterly of research and planning in higher education, 14 (47): 97-131.

Bordbar, Gholamreza, Karimi, Ozhan, Zare, Naser (2012). Identification of elements and patterns of competent- selection for optimization of succession planning model in personnel). Two quarterlies of human resources management studies, Comprehensive Imam Hossein (PBUH) University, 4th year, vol. one: 87-114.

Pasbani M., Azar Kasb A., Fatehi Khashenkab L., Arastoo E. (2014). Recognition of 
organizational culture based on Denison model (Case study: Shiraz Floor Factories Complex \& Dadli (TINA)), Journal of organization vculture management, series 12, vol. 4, pp. 741-761.

Taboly, Dr. Hamid \& Mohammad Jafaripour (2015). Review on relationship among succession planning with organizational thriving, The 1st international conference on management, economy, accounting and training sciences, Sari, Ayandehsaz scientific-research and consulting Company, Payam-E-Noor University, Neka Branch.

Jokar A., Maleki M.H. (2017). Presentation of a framework to measure readiness of companies from perspective of succession planning with the combined approach of grey network analysis process and DIMETEL, Journal of modern researches in decision msjking, series 2, vol. 1, pp. 73-94.

Derakhshideh H. V., Ansari M.A (2014). Analysis on effect of managerial competency and commitment of management to empowerment of personnel with their job performance (Case study: Bank personnel), Scientific- research journal of management and development process, series 27, vol. 1: pp. 73-114.

Zakeri M., Faqihi A., Daneshfard K. (2015). Interpretation of succession planning pattern for director by benefitting from story of Adam (PBUH) as Caliph of God based on exegetic paradigm from Ayatollah Javadi Amoli, Scientific- research journal of Islamic management, 23rd year, vol. 1: 41-64.

Ranaei H., Soltani M., Yazdani M. (2012). Recognition and ranking of competency dimensions and elements in directors: Content analysis on competency model for directors. Quarterly of human resources studies, vol. 23: 1-20.

Zeinolabedin Bidmeshki Zohreh, Adli Fariba, Vaziri Mojdeh (2014). Comparison of status quo of succession planning and talent management with the favorable status in higher education, Journal of research and planning in higher education, series 20, vol. 2 (serial 72): 51-72.

Shojaei, Samereg, Sepideh Adib, \& Mehdi Zanganeh (2014). Review on importance of succession management in managing of talents, The first national conference of Researches and Development (R\&D) in third millennium, Ali Abad Katoul, Islamic Azad University, branch of Ali Abad Katoul.

Abbasi, Zohreh, Mehri Parirokh (2009). Analysis of effect of organizational culture on implementation of knowledge management in central libraries of universities affiliated to Ministry of Sciences, Researches and Technology, the second national conference of management, Tehran: Communication Institute of Oil, Gas, and Petrochemistry.

Gholipour A., Yazdanfar S. (2012). Recognition of succession planning challenges in household businesses (Case study in Food industry at Tehran Province). Social, Economic, Scientific, and Cultural Journal of Business and Society, vol. 49: 6-12.

Kazemi Moghadam Ali, Mohammad Hassan Ghasemi Nameghi, Seyed Ali Akbar Ahmadi (2012). Executive requirements for implementation of succession planning in Fajr Petrochemical Company, the first national conference on study of strategies for improvement in subjects of management, accounting, and industrial engineering at organizations, Gachsaran, Islamic Azad University, Gachsaran branch.

Monavarian, Abbas, Shirin, Ali (2003). The relationship among organizational culture and organizational structure.

Monavarian, Abbas, Bakhtaei, Amir (2007). Recognition of organizational culture based on Denison model (Case study: Institute of Industrial Management, The fourth international conference of management, Tehran.

Yeganegi, A. (2010). The role of competency of directors in effectiveness of management (Case study: Telecommunication Company- Qazvin Province), Journal of management and development and change, 5: 57-68. 
Basiri .Abdolmajid, Sabegh. Zeinolabedin Amini. (2014).Organizational Factors Influencing Succession Planning Managers in Khuzestan Province

Conger, J., Fulmer, R. (2003). Developing your Leadership Pipeline. Harvard Business Review, Vol. 81.No.12.pp.76-84.

Cross, J. 2010. Engaging the paradox of competence: business and education research, develop a master of business competence model. Doctoral Thesis. Capella University.

Dessler, Gary (2008). Human Resource Management. 11th ed. New Jersey: Pearson Prentice Hall.

Dubois, D. D., Rothwell, W. J., Stern, D. J., \& Kemp, L. K. (2015). Explain the relationship between managers' competency to successfully governmental organizations. Engineering Management Journal, Vol. 22 No. 1, PP.3-12 .

Edward Staehr, (2015) "Human resource risk and succession planning: Implementing an integrated personal and financial consulting model in New York State", Agricultural Finance Review, Vol. 75 Iss: 1, pp.133 - 139.

Elenaa, F., Oksanab, Y., Larisac,B and Yurieva Olgad,Y,2015, Role of Competence-Based Approach in an Increase of Efficiency of Public Administration, Procedia Economics and Finance $23: 1064-1067$

Ennis, M.R. (2008). Competency models: a review of the literature and the role of the employment and training administration (ETA). U. S. Department of labor. January 29,5.

Fang, C.H., Chang, S.T., and Chen, G.L. (2010), Competency development among Taiwanese healthcare middle manager: A test of the AHP approach, African Journal of Business Management Vol. 4, No. 13, pp. 2845-2855.

Jarbou H. (2010) "The current state of succession planning in major non- Governmental organizations (NGOs) in the gaza strip"; Library Management, Vol. 31, No.4/5, pp.50 60.

Kaplan, B. (January-February 2008). “Leveraging Our Critical Knowledge.” Defense AT\&L magazine, p. 11.

Kim, Y. (2006). Measuring the Value of Succession Planning and Management: A Qualitative Study of U. S. Affiliates of foreign multinational companies, Dissertation Submitted in The Pennsylvania State University.

Kotonen, U., Savonen M-L., Tuominen, U., Lahtinen, H. \& Suomrki, A. 2012. Process and methods of competence management and development. In -Kotonen, U. \& Suomrki, A. (ed.) Competence development of logistics centers: development of logistics centers in Southern Finland. The publication series of Lahti University of Applied Sciences. 22-28.

Mehrtak, M., Vatankhah, S., Delgoshaei, B., \& Gholipour, A. (2014). Succession Planning in the Iranian Health System: A Case Study of the Ministry of Health and Medical Education. Global journal of health science, 6(5), 174.

Mugo. Mary, David Minja, Lily Njanja .(2015).The Mediating Effect of Culture on Management Succession and Corporate Growth Strategy among Local Family Businesses in the Manufacturing Sector in Nairobi County, -Kenya, European Journal of Business and Management, ISSN 2222-1905 (Paper) ISSN 2222-2839 (Online) Vol.7, No.5, 2015

Pandey, S., \& Sharma, D. (2014). Succession Planning Practices and Challenges: Study of Indian Organisations. Procedia Economics and Finance, 11, 152-165.

Romejko, M.A., (2008). Key Characteristics of a Succession Planning Program at a Government research Center, Dissertation Submitted to Pepperdine University.

Rothwell, W.J..(2005), Effective Succession Planning: Ensuring Leadership Continuity and Building Talent from Within. American Management Association (AMACOM). New York. 3rd Edition.

Sanghi, S. 2007. The Handbook of Competency Mapping. New Delhi: Vivek Mehra for SAGE Publications India Pvt Ltd. 
Santora .Joseph C., Bozer. Gil, (2015) "How nonprofit organizations can ensure stability and sustainability through succession planning: make HR a strategic partner in the process", Strategic HR Review, Vol. 14 Iss: 6

Shabankareh, N., Madani, N., \& Shiralizadeh, W. (2015). The Relationship between Organizational Culture and Employee Succession Planning in Keshavarzi Bank Branches in Tehran. International Journal of Academic Research in Business and Social Sciences, 5(4), 198-210.

Skorková, Z, 2016, Competency models in public sector, Procedia - Social and Behavioral Sciences, 230, $226-234$.

Whitman, M. V, \& Valpuesta, D. (2010). Examining Human Resources' Efforts to Develop a Culturally Competent Workforce. The Health Care Manager, 29(2), 117-125. 